\title{
3D DOCUMENTATION AND VIRTUAL ARCHAEOLOGICAL RESTORATION OF MACEDONIAN TOMBS
}

\author{
M. Stampouloglou ${ }^{1}$, O. Toska ${ }^{2}$, S. Tapinaki ${ }^{3}$, G. Kontogianni ${ }^{3}$, M. Skamantzari ${ }^{3}$, A. Georgopoulos ${ }^{3 *}$ \\ ${ }^{1}$ Serres Ephorate of Antiquities, mastam40@gmail.com \\ 2Department of Mediterranean Studies, University of the Aegean msmarch16036@aegean.gr \\ ${ }^{3}$ Laboratory of Photogrammetry, National Technical University of Athens \\ sevi@survey.ntua.gr, gkondog@central.ntua.gr,mskamantz@central.ntua.gr,drag@central.ntua.gr
}

\section{Commission II, WG II/8}

KEY WORDS: 3D documentation, Image based modelling, laser scanning, virtual restoration

\begin{abstract}
:
Archaeology as a science is based on finding and displaying the remains of the past. In recent years, with the progress of technology, the science of archeology has been expanding and evolving. Three-dimensional digitization has become an integral part of the archiving, documentation and restoration effort of cultural heritage, offering important benefits in studies for reconstruction and restoration tasks of architectural creations, archaeological sites, historic monuments and objects of art in general. The threedimensional models are now available for many applications. In this paper such 3D models of two prominent Macedonian tombs in Northern Greece were exploited for their virtual restoration. Virtual restoration of monuments is of special importance to archaeological research, as it provides the necessary tools to investigate alternative solutions to the serious issue of archaeological restoration. These solutions do not interfere with the real monument, thus respecting its value and the international conventions. Digital 3D models have begun to be more beneficial in a science such as archaeology as they offer easy access to both archaeological and geometric information to a wider audience as well as a high degree of interaction possibilities with the user.
\end{abstract}

\section{INTRODUCTION}

\subsection{General Instructions}

Nowadays contemporary technologies have greatly contributed to the geometric documentation of monuments, a process which is a necessary part of their restoration and exploitation. Threedimensional digitization has become an integral part of the archiving and documentation effort of cultural heritage, offering important benefits in studies for reconstruction and restoration tasks of architectural creations, archaeological sites, historic monuments and objects of art in general. However, there is great potential in the resulting three-dimensional models, which, as current digital technologies are progressing, become more realistic, more accurate and more manageable by common computers and, especially, by non-experts. Hence, recent international literature is rich with numerous interesting investigations for the alternative uses of three-dimensional models, mostly in the virtual domain. Virtual restoration of monuments is of special importance to archaeological research, as it provides the necessary tools to investigate alternative solutions to the serious issue of archaeological restoration. These solutions do not interfere with the real monument, thus respecting its value and the international conventions.

This paper focuses on the process of geometric documentation of two prominent Macedonian tombs dating from the 3rd century BC and located in Macedonia in Northern Greece (Figure 1). In particular, the two Macedonian tombs, both named after their excavators, are (i) the tomb at Langadas, known as the "tomb of Macridy Bey" in Derveni, Thessaloniki Prefecture (Figure 2) and (ii) "the tomb of Heuzey" or else the tomb of Pydna in Korinos of Pieria, near Katerini (Figure 3).

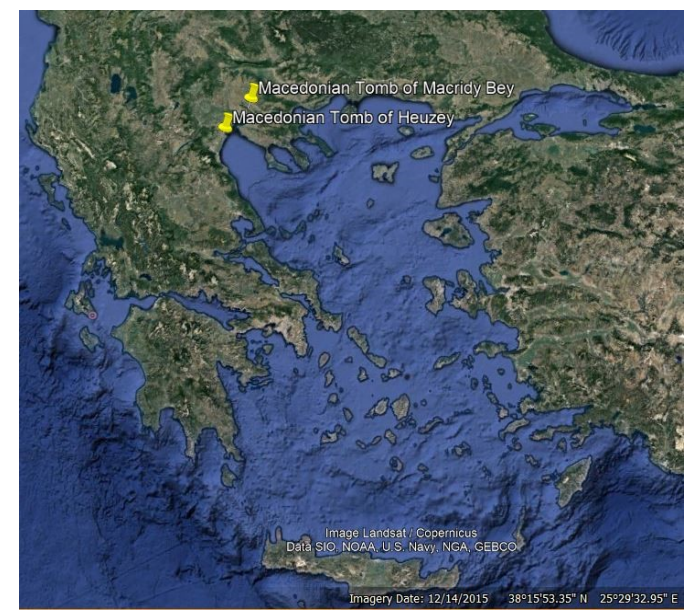

Figure 1: The location of the two Macedonian tombs in Northern Greece

The paper is organized in four sections. In the first section an historic and archaeological description of the Macedonian tombs and especially of the two documented here is presented. In the second section the data acquisition methodology for the geometric documentation of the two tombs is briefly described along with the necessary data processing to produce the $3 \mathrm{D}$ textured models. In the third section the attempts for their

\footnotetext{
* Corresponding author
} 
virtual restoration are presented. Finally, in the fourth section the above actions are evaluated, and some concluding remarks are highlighted.

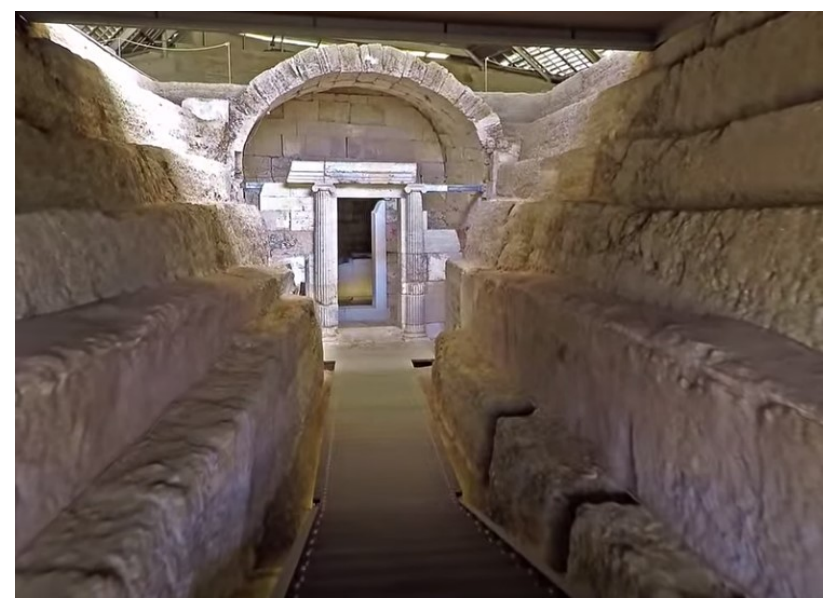

Figure 2: The Macedonian tomb of Macridy Bey

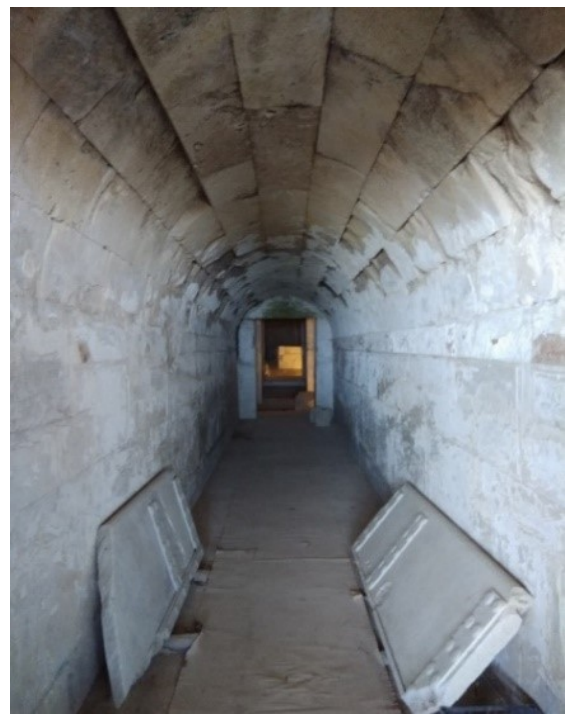

Figure 3: The Macedonian tomb of Heuzey

\section{HISTORIC REFERENCE}

\subsection{The Macedonian tombs}

In the middle of the $4^{\text {th }}$ century $\mathrm{BC}$, a new form of monumental architecture made its appearance in Macedonia, for the first time in the Greek world, the so-called Macedonian tomb. These monuments serve as a manner of burial, initially for the kings and then for the upper social classes (Ginouves 1993). The term "Macedonian tomb" depicts not only the first appearance of this monument in the kingdom of Macedonia, but also its geographical distribution, which is mainly in areas under Macedonian influence or occupation (Saatsoglou-Paliadeli 2011).

Two main features segregate these burial constructions from all the others and classify them as a separate group: their barrelvaulted roof and their monumental façade. These structures were built underground and were covered by an artificial earthen "tumulus", easily noticed from afar (Miller 1982). A
Macedonian tomb usually consists of a burial chamber and/or one or two antechambers, and sometimes a passageway, called dromos, leads to the entrance of the main chamber permitting the burial procedure. These tombs have architecturally shaped façades, which are either elaborate and monumental in a Doric or Ionic style or very simple. The tomb's entrance is often closed either by marble or wooden doors, while simultaneously the external entrance is blocked by stone blocks consecutively positioned. The façades and interior walls are decorated with plaster and usually painted with bright colors, like red, yellow, green, black and blue (Pantermalis 1972, Gossel 1980, Fedak 1990, Miller 1972, Miller 1993, Ginouves 1993, Huguenot 2008).

\subsection{The Macedonian tomb of Heuzey}

The Macedonian tomb of Heuzey is located $10 \mathrm{~km}$ from Katerini and $2.5 \mathrm{~km}$ northwest of the community of Korinos at Pieria in Northern Greece (Heuzey \& Daumet 1877, Miller 1972, Gossel 1980, Miller 1982, Pantermalis 1985, Besios 1991, Miller 1993, Sismanidis 1997, Giannakis et al. 2000, Besios 2010, Descamps-Leguime 2011, Mangoldt 2012). The same location in antiquity was part of the main road, connecting ancient Pydna to southern Pieria (Figure 1). The discovery of the Macedonian tomb of Heuzey, otherwise the tomb of Pydna, is attributed to the French archaeologist and explorer Léon Heuzey, who toured central Macedonia in 1855-56. The owner of a plot at Korinos, near ancient Pydna, allowed L. Heuzey to excavate an underground funerary monument whose brilliantly decorated upper parts were still visible. In 1861 Heuzey returned to Macedonia as a leader of a research mission, under the protection of Napoleon III. In this journey Heuzey was accompanied by the architect Honore Daumet and they decided to look for this tomb again. This tour is the first excavation research in northern Pieria. Daumet provides paintings and drawings with color, which are very useful for the understanding of the tomb's condition at that time and especially for its decoration. It has been more than a century when 1991 the tomb of Heuzey was once again unearthed by archaeologist M. Besios, after its re-covering by natural phenomena over the years.

The tomb is covered by a large tumulus of $60 \mathrm{~m}$ diameter and $15 \mathrm{~m}$ height. It is located well away from the tumulus center (Figure 4a) and it is a large tomb of the Macedonian type with Doric façade. It consists of an antechamber and a main burial chamber with two funerary beds. A sloping road (dromos) with barrel-vaulted roof leads to the tomb. In a later construction phase, a second barrel-vaulted antechamber was added to the original tomb, along with the tomb's dromos. The two antechambers and the main burial chamber are covered by a continuous barrel-vaulted roof (Figure $4 b$ ).

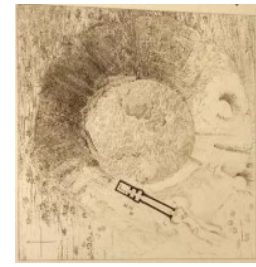

(a)

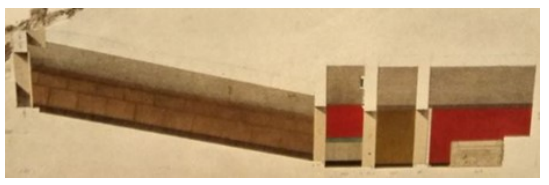

(b)
Figure 4: The Macedonian tomb of Heuzey

The tomb was built in the pseudo-isodomic system. Its floor consists of coarse rectangular stone slabs covered by a thick red plaster layer with small pebbles. The excavation of 1991 
revealed the ruins of another corridor in front of the tomb's entrance. The corridor consists of two sidewalls, which at their upper part are made of mud bricks and at the base are built of two rows of cornerstones. Through the wooden elevated modern structure, which leads to the tomb, the visitor can see the ancient ruins of this exterior corridor. The interior walls of the dromos are covered with mortar and they are painted. White paint for the vault, marble imitation for the transition from the side wall to the arch and black for the base, but a few traces of this decoration are now visible. The walls of the first antechamber were also painted: white vault, red zone and black plinth. Rare and unusual is the formation of the Doric façade on the back wall. The monument's façade is constructed in the Doric style and comprises pillars, triglyphs, metopes and pediment.

The second antechamber was also covered with colored mortar, mostly yellow. On the walls of the main chamber remaining traces of color show that there were four painted zones alternating among black on the base, red, blue-black and white at the top. In the tomb the broken two-leaved door of the dromos was found (Figure 3), along with the door of the main chamber and the decorated faces of the two beds. One bed depicts a relief decoration of a dog with thick fur, while the other bears a relief representation of a coiled snake (Figure 5). The broken door of the passageway and the snake relief are still in the tomb, while the door of the main chamber and the relief decoration of the dog are now displayed in the Louvre museum.
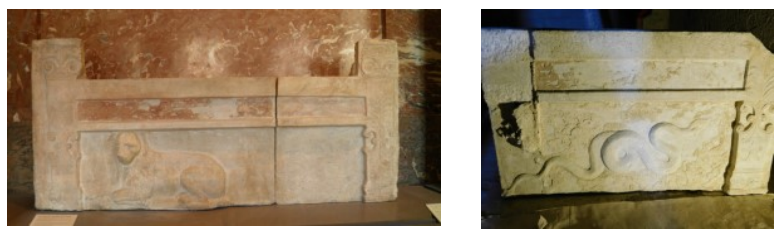

Figure 5: The burial beds with the depictions of a dog (left) and a snake (right)

The Macedonian tomb of Heuzey is an extreme example of disagreement among researchers, as there are several deviations in its dating, which range from the end of the $4^{\text {th }}$ century to the beginning of the $2^{\text {nd }}$ century BC. The most prevalent dating is at the end of the 4 th and the beginning of the 3rd century.

\subsection{The Macedonian tomb of Macridy Bey}

The Macedonian tomb of Langadas or the 'tomb of Macridy Bey' is situated on the east end of the ancient cemetery of Derveni, $9 \mathrm{~km}$ northwest of Thessaloniki, next to the Thessaloniki - Langada highway (Macridy 1911, Büsing 1970, Miller 1972, Pantermalis 1972, Gossel 1980, Sismanidis 1985, Sismanidis 1997, Tzanavari 1997, Tzanavari 2000, Mangoldt 2012, www.macedoniantombmacridybey. culture.gr.). The narrow passage of Derveni was part of the ancient Egnatia Odos and belonged to the vital area of ancient Liti, one of the most important Mygdonian cities (Themelis \& Touratsoglou, 1997). The tomb was discovered looted in February 1910 after a strong earthquake in the area and was excavated a few months later by the Ottoman officer Theodoros Makridis (Thessaloniki was still under Turkish occupation), who revealed the façade, which had already collapsed, and the interior of the tomb (Figure 6).

The passageway (dromos) that leads to the entrance of the tomb was partially revealed many decades later, in the 1990's, by excavation supervisor $\mathrm{K}$. Tzanavari of the responsible Ephorate of Antiquities of the Ministry of Culture. During the excavation, part of the ancient tumulus was removed resulting in a vertical slope more than 12 meters high which subsequently suffered erosion due to rainfall. Works were interrupted in 2008 till the implementation of the monument's restoration study that was meanwhile prepared by the authorized Ephorate of Antiquities (Athanassiou et al 2012, Athanasiou et al. 2015). The restoration project began in 2012 with funding from the National Strategic Reference Framework (NSRF) 2007-2013 and was completed in 2015 (Figure 6).
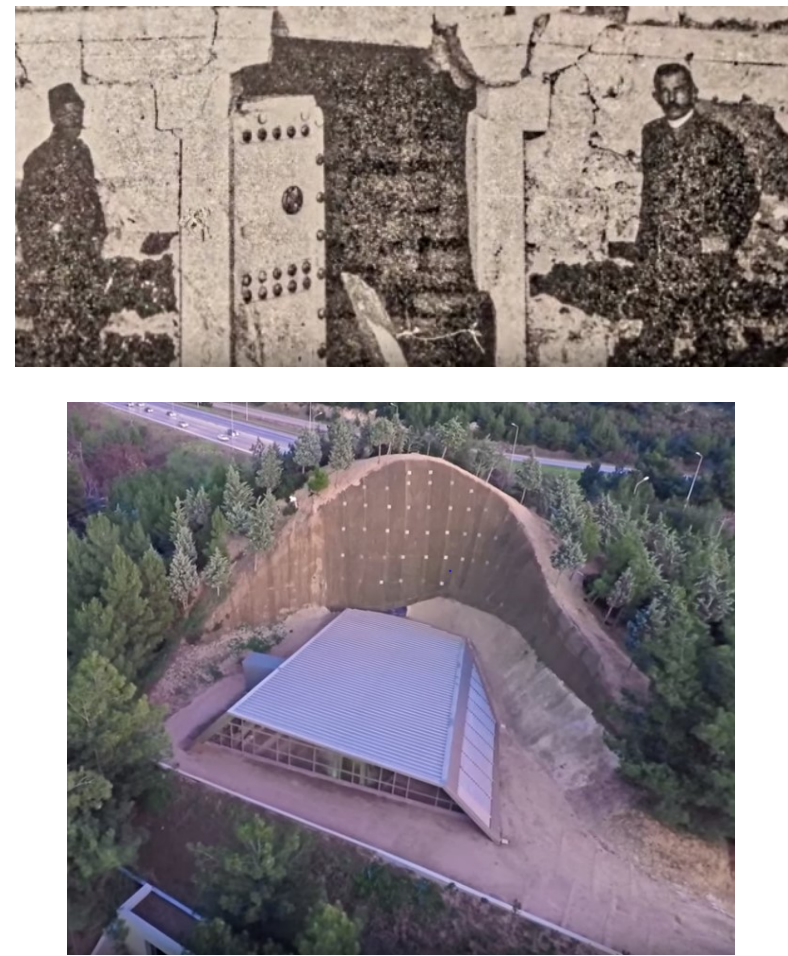

Figure 6: Macridy Bey (top) in front of the burial chamber in 1910 and view of the Macedonian tomb of Macridy Bey after its restoration in 2015 (bottom)

The Macedonian tomb of Langadas or 'The tomb of Macridy Bey' was a monumental structure built for the burial of a single distinguished individual somewhere between the end of the 4th and the beginning of the 3 rd century BC. It is one of the biggest double-chambered Macedonian tombs (Figure 7). The antechamber and the burial chamber were built in the pseudoisodomic system with blocks of a brownish limestone laid without mortar in nine layers. They were both covered, but separately, with a barrel-vaulted roof. The tomb was covered by a large tumulus, 19 meters high and 75 meters wide, the greater part of which remains preserved today. This artificial hill was constructed after the burial of the deceased by laying soil material in successive layers with a thickness of about 0.80 meters.

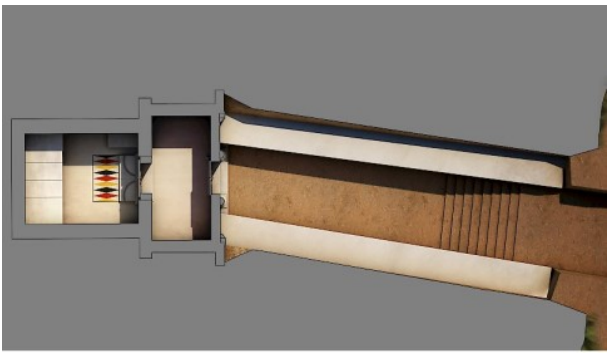

Figure 7: Floor plan of the tomb of Macridy Bey 
The sloping road (dromos), which led to the entrance of the tomb, was also covered by the mound. The road was more than 14 meters long and had a width of 3.50 meters. There were steps at its west end (Figure 8). It had $2 \mathrm{~m}$ high side walls made of mud bricks and its floor was coated with a mixture of clay and gravel. It ended right in front of the tomb's façade. The façade is architecturally formed in the Ionic style and consists of a tetrastyle, a frieze and a pediment (Figure 8). In the center of the façade there was a two-paneled wooden door with gilt bronze decoration. The façade was covered with colored mortar. Its traces indicate that the tympanum of the pediment was bright yellow framed by purple while the column capitals and architrave were red and blue.
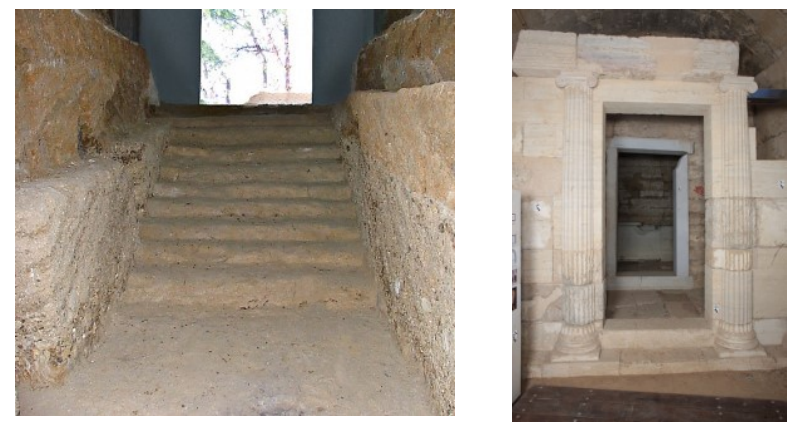

Figure 8: The staircase at the beginning of the dromos (left) and the monumental Ionic façade (right).

The antechamber, smaller but wider than the burial chamber, was also covered with colored mortar partially preserved nowadays. There were five painted zones alternating among black on the base, white, grey, red and white at the top. A marble two-paneled door - transported and nowadays exhibited at the Istanbul Archaeological Museum - led to the burial chamber hosting a unique burial structure $1.30 \mathrm{~m}$ high. It is divided inside in two spaces of unequal size: the sarcophagus and the case. Beneath this construction a cist tomb was found containing the remains of a wooden coffin indicating the place where the deceased was buried.

\section{GEOMETRIC DOCUMENTATION}

This study focuses on two objectives. The first one is the creation of three-dimensional models of these two Macedonian tombs, conducted with an integrated approach, in which the classic topographic survey with a total station has supported modern Geomatics techniques, such as the Structure from Motion (SfM) and Multi-View Stereo (MVS) and the Terrestrial Laser Scanning. The second objective is the partial virtual restoration, which has been attempted based on the created 3D models, as well as a photorealistic visualization by means of a virtual tour on the case of the Heuzey's tomb.

\subsection{Data Collection}

Firstly, a three-dimensional geodetic network was established, which is necessary for the geometric documentation of a construction. A network of four (4) stations was established for the Macedonian tomb of Heuzey and six (6) for the Macedonian tomb of Macridy Bey. The networks were measured carefully and adjusted to form a sound basis for the georeference of all subsequent measurements. All network measurements and those for the determination of the control points were performed using the TOPCON GT 3003 Total Station.
The next important step, after setting up a network and the measurement of the coordinates of the control points, was the photographic coverage. The tombs were densely photographed with a Canon EOS 1Ds Mark III (DSLR-AF-AE) camera, which employs a CMOS, full frame sensor $36 \times 24 \mathrm{~mm}$. Furthermore, a Canon EF f/ 2.8L II USM zoom lens with $16 \mathrm{~mm}-35 \mathrm{~mm}$ focal length range was used for the Macedonian tomb of Heuzey. For the Macedonian tomb of Macridy Bey, a Canon EF-S $24 \mathrm{~mm}$ $\mathrm{f} / 2.8$ STM standard lens was employed. The tombs were illuminated by two Bowens Duo Lite studio flashlights with their control panel and equipped with two $40 \times 50 \mathrm{~cm}$ soft boxes in order to reduce harsh shadows.

Digital photography was acquired in such a way to enable as much as possible the automatic alignment by the SfM algorithm. Dense overlapping images were taken covering all details of the two monuments as well as possible. Coded targets were put in strategic positions in order to enable the scaling and georeferencing of the 3D model.

The final step in data collection process was the collection of the $3 \mathrm{D}$ information of the tombs in the form of point clouds using the FARO 3D 330X terrestrial laser scanner. The density of the point clouds was set to $3-5 \mathrm{~mm}$ depending on the distance of the scan stations from the object. Chessboard targets were put on the object in order to assist the alignment and georeferencing of the individual scans. In Table 1 the summary of the data collected is presented.

\begin{tabular}{|l|c|c|c|c|}
\cline { 2 - 5 } \multicolumn{1}{c|}{} & \multicolumn{2}{c|}{$\begin{array}{c}\text { Macedonian tomb of } \\
\text { Heuzey }\end{array}$} & \multicolumn{2}{c|}{$\begin{array}{c}\text { Macedonian tomb of } \\
\text { Macridy Bey }\end{array}$} \\
\hline Images & 539 & $5.4 \mathrm{~GB}$ & 546 & $5.8 \mathrm{~GB}$ \\
\hline Scans & 7 & $3.2 \mathrm{~GB}$ & 15 & $6.4 \mathrm{~GB}$ \\
\hline
\end{tabular}

Table 1: Data collected for the 3D modelling

\subsection{D Model Creation}

Suitable processing of the acquired data enabled the exploitation of the raw material for the creation of the 3D models of both Macedonian tombs. The geometric documentation included, of course, the production of 2D products with orthophotographs. However, the scope of this paper is the virtual restoration, for which the $3 \mathrm{D}$ textured models are necessary.

The creation of the 3D model of the Macedonian tomb of Heuzey consists of three main stages. Initially, the Faro Scene ${ }^{\circledR}$ software was used for processing the point clouds, which were recorded by the laser scanner. This data was exported from the laser scanner and imported into the Faro Scene ${ }^{\circledR}$ software for processing. The software automatically detects the chessboard targets, which were placed on the monument during the data collection. Next, the point clouds of the seven scans were registered and merged and the final point cloud of the entire monument was created (Figure 9). Some cleaning of noise and intelligent decimation was performed for creating a more manageable point cloud.

Secondly, the processing of the images for their alignment and for the creation of a three-dimensional model of the tomb was performed in Agisoft Photoscan ${ }^{\mathbb{B}}$ software. After evaluating and archiving the captured photos, each room of the tomb was individually edited in chunks, following the automated software steps. These chunks were later merged, and the dense point 
cloud of the tomb was created. This cloud was exported to Geomagic ${ }^{\circledR}$ Studio software for further processing.
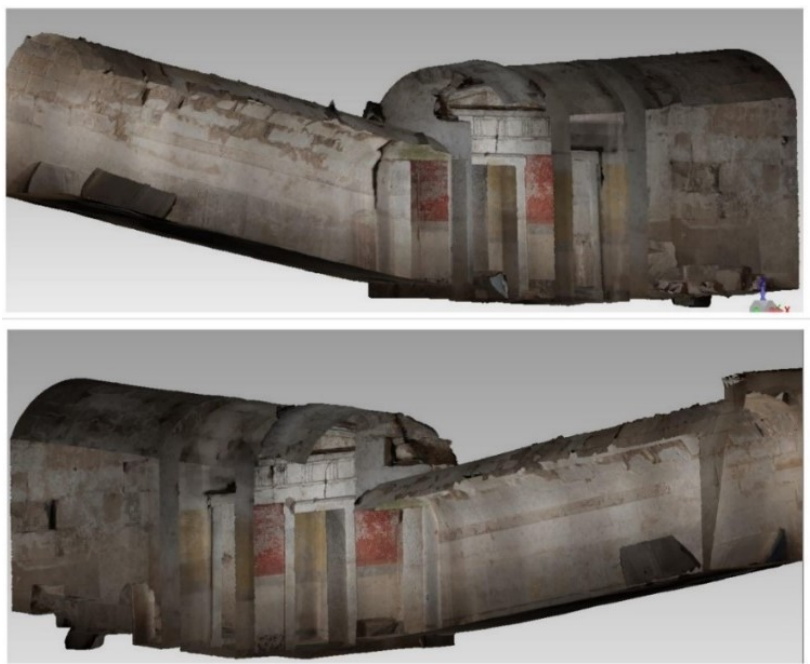

Figure 9: 3D model creation of the Macedonian tomb of Heuzey

Thirdly, the point cloud from Faro Scene and the dense point cloud from Photoscan were combined to create the final 3D model of the tomb. These point clouds were imported into the Geomagic $^{\circledR}$ Studio software to be merged in order to fill eventual gaps. Then, following the automated software steps a surface (wrap) of the tomb is created. At this point, it was decided to remove the modern shelter with the railings from the final model, as it was incomplete and contained misleading information. Of course, as it is a modern construction its removal does not affect the ancient construction.

The completed model of the Macedonian tomb was imported into the Photoscan ${ }^{\circledR}$ software for the generation of the texture and color from the aligned images, which is the final step of creating the three-dimensional model.

For the creation of the 3D model of the Macedonian tomb of Macridy Bey we followed all four stages suggested by the Agisoft Photoscan ${ }^{\circledR}$ software. Separate chunks were created respectively to the captured photos of each "room" of the tomb with the exception of the tomb's passageway (dromos) where the acquired images could not be aligned due to the extreme uniformity of the dromos' walls and the software's inability to detect and match points on such a surface.

Following the merging of the chunks and the building of the dense point cloud, the 3D polygonal model was built and then textured (Figure 10). None of the laser scanner data was used as it was considered unworthily time consuming for the partial virtual restoration of the monument that was being attempted.

\section{VIRTUAL RESTORATION}

Restoration of monuments is a very delicate action. Thorough studies should be compiled and ample time for exchange of opinions is always necessary before a restoration is implemented. This is especially true in cases of reconstructing damaged monuments irrespective whether the original pieces are available or not.

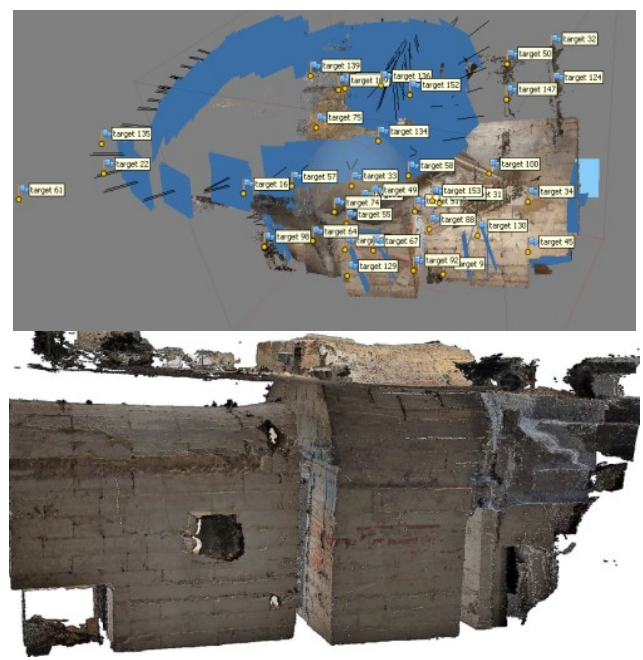

Figure 10: 3D model creation of the Macedonian tomb of Macridy Bey

Virtual restoration opens new possibilities, as it enables the restoration in a virtual environment and indeed of many different solutions. This allows for evaluating the various solutions before any physical intervention in the monument itself. This action has been attempted in the past in many cases with successful results (De Fuentes et al. 2010, Lentini 2009, Matini et al. 2009, Patey-Horvath 2011, Valle Melon 2005, Kontogianni et al. 2013).

Both these two cases described in this paper are ideal for attempting virtual restorations, because the architectural elements have been moved to distant museums or they are simply stored in a place different than their original position. These included the two doors and the beds in the case of the tomb of Heuzey and the pediment of the tomb of Macridy Bey. These virtual restorations were attempted and were carried out by the archaeologists themselves, with the technical assistance of the photogrammetrists and technical experts. Consequently, this is a fine example of bridging the gap with the close cooperation of users and providers.

\subsection{Virtual Restoration of the Macedonian tomb of Heuzey}

In the case of the Macedonian tomb of Heuzey two partial virtual restorations have been attempted, which are related to the virtual displacement of the two-leaved marble door of the entrance and the one bed of the burial chamber to their original positions. These actions were performed after a thorough archaeological study. Specifically, the marble doors were placed for their safety on the side walls of the Macedonian tomb "dromos", by the archaeologists, while their original position, based on the designs of the first archaeologist who discovered the tomb, are at the entrance of the tomb. Using contemporary technological tools (e.g. Geomagic Studio software) the two door leaves were virtually restored (Figure 11).

Furthermore, the façade of the bed with the snake relief was moved by the ancient tomb looters in the middle of the burial chamber, while its original position was at the left corner of the chamber, based on the designs of the first researchers of the tomb (Figure 12). This was also virtually translated to its original place with the help of the above tools (Figure 13). 


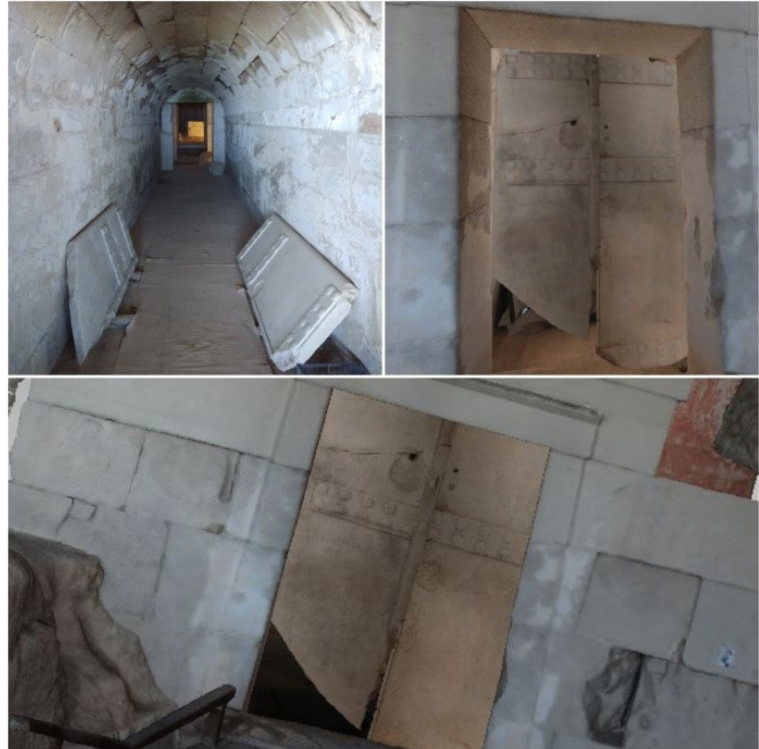

Figure 11: The virtual restoration of the marble door of the Macedonian tomb of Heuzey

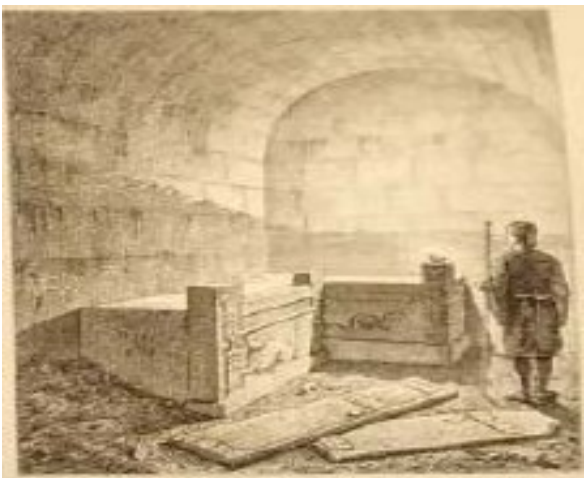

Figure 12: The chamber and the beds as found by the French in 1861 in the tomb of Heuzey
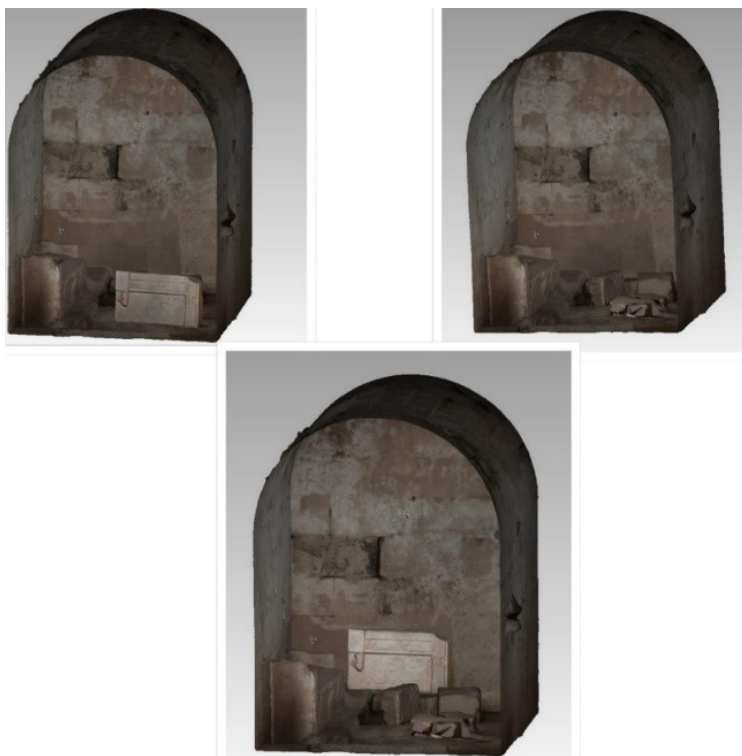

Figure 13: The virtual restoration of the burial bed of the Macedonian tomb of Heuzey

\subsection{Virtual Restoration of the Macedonian tomb of Macridy Bey}

During the restoration of the Macedonian tomb of Macridy Bey in the current decade, scattered blocks and architectural members from the façade were collected and identified by archaeologists and architects working together. Due to the deformation at the ends of the façade's wall, the intervention was confined to the restoration of its central part, which showed no deviation from its vertical alignment. The two semi-columns, the north part of the wall, and the central part of the architrave were restored, while the re-positioning of the surviving parts of the pediment's cornice proved prohibitive.
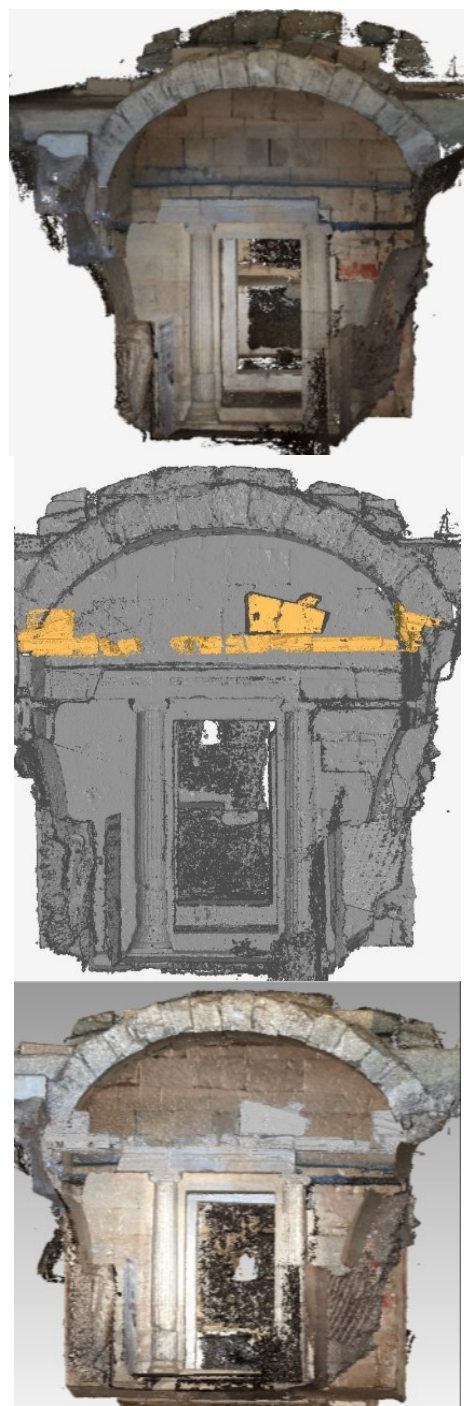

Figure 13: The virtual restoration of the Macedonian tomb of Macridy Bey

For obvious safety reasons, the surviving parts of the pediment were placed on an artificially made platform above the tomb's vaulted roof taking their original place to the formation of the pediment.

Modern technology, using Geomagic ${ }^{\circledR}$ software, enabled this virtual restoration which was confined to the repositioning of the architectural parts whose original place was undoubtful. Virtual restoration was performed with the object mover tool which allows the user to move or rotate an object manually. 
This command works on any type of object. The moved objects were isolated from the entire 3D model, moved to their original location and finally merged with the model (Figure 13).

In this way, today's visitors are able to better understand the monument's original appearance even if safety reasons prohibit an actual physical restoration which is the exact case of the pediment's restoration in the Macedonian tomb of Macridy Bey.

\section{EVALUATION AND CONCLUDING REMARKS}

It has been shown that the virtual restoration of the two tombs using the $3 \mathrm{D}$ models produced by contemporary techniques of digital documentation is possible and can be successful. It has also been established that interdisciplinary cooperation is of utmost importance for such tasks.

The virtual restorations attempted to reassemble the tombs by moving the construction elements and positioning them in their original position, as their physical restoration could not be safely performed due to obvious technical reasons. These archaeological restorations have been performed based on thorough archaeological studies, which determined the most probable original position of the restored parts. These tasks have not interfered with the original monuments as they are now, thus enabling multiple alternatives to be studied.

For both cases further actions could be proposed. Namely 3D models of the parts exhibited in foreign museums, Louvre and Istanbul museum, could be produced. These models could be introduced into their original positions in the 3D models of this study and virtually completely restore the tombs.

\section{REFERENCES}

Athanasiou, F., Malama, M., Miza, M., Sarantidou, M., Papasotiriou, A. 2012. The resoration of the Macedonian tomb Macridy Bey in Derveni of Thessaloniki. $3^{\text {rd }}$ Panhellenic Conference of Restorations (ETEPAM). Athens, 1-3 November 2012 (in Greek).

Athanasiou, F., Malama, M., Miza, M., Sarantidou, M., Papasotiriou, A. 2015. The restoration of the facades of the Macedonian tomb Macridy Bey in Derveni of Thessaloniki. $4^{\text {th }}$ Panhellenic Conference of Restorations (ETEPAM). Thessaloniki, 26-28 November 2015 (in Greek).

Besios, M., 1991. Excavation researches in Northern Pieria. AEMTh 5, 171-178. Thessaloniki, Min. of Culture, Min. of Macedonia \& Thrace and AUTh (in Greek).

Besios, M., 2010. Wreath of Pieria: Pydna, Methoni and the antiquities of Northern Pieria. Katerini, A.F.E. (in Greek).

Büsing, H., H., 1970. Die griechische Halbsäule. Wiesbaden, Franz Steiner Verlag GMBH.

De Fuentes F. A., Valle Melon J.M., Rodriguez Miranda A. 2010. Model of sources: a proposal for the hierarchy, merging strategy and representation of the information sources in virtual models of historical buildings. CAA conference Proceedings,
"Computer Applications and Quantitative Methods in Archaeology", Granada.

Descamps-Lequime, S. 2011 (Edit.). Au royaume d'Alexandre le Grand: La Macédoine antique. Paris: Louvre editions.

Fedak, J. 1990. Monumental tombs of the Hellenistic Age: A Study of Selected tombs from the Pre-Classical to the Early Imperial Era. Phoenix. Supplementary volume: 27. Toronto: Buffalo: London: University of Toronto Press.

Giannakis, G., Calogeridis, P., Besios, M. 2000. Protection presentation of Macedonian tombs of Korinos AEMTh 14, 395 405. Thessaloniki 2002, Min. of Culture. \& AUTh (in Greek).

Ginouvès, R. 1993. Macedonia from Philippos B up to the Roman conquest. Athens, Ekdotiki Athinon.

Gossel, B. 1980. Makedonische Kammergraeber. Berlin: Monath's KopieDruck.

Heuzey, L., A., Daumet, H., 1877. Mission archéologique de Macédoine. Paris, Firmin-Didot et Cie.

Huguenot, C., 2008. La tombe aux Erotes et la tombe d' Amarynthos. Architecture funéraire et présence macédonienne en Grèce centrale. Eretria XIX. Lausanne: Infolio Editions.

Kontogianni, G., Georgopoulos, A., Saraga, N., Alexandraki, E. and Tsogka, K., 2013. 3D Virtual Reconstruction of the Middle Stoa in the Athens Ancient Agora, Int. Arch. Photogramm. Remote Sens. Spatial Inf. Sci., XL-5/W1, 125-131, doi:10.5194/isprsarchives-XL-5-W1-125-2013, 2013.Lentini D., 2009. The funeral area in "Ponte Della Lama Canosa" (IIIVI century) an hypothesis of 3D historical- monumental reconstruction, Proceedings of 3DArch, Trento, Italy, February 25-28.

Macridy, Th. 1911. "Un tumulus Macédonien á Langaza.” JDAI 26, 193-215.

Mangoldt, H. v. 2012. Makedonische Grabarchitektur: Die Makedonischen Kammergräber und ihre Vorläufer. Band I \& II. Tübingen: Verlag Ernst Wasmuth.

Matini M.R., Einifar A., Kitamoto A., Ono K., 2009. Digital reconstruction based on analytic interpretation of relics: case study of Bam citadel. XXII International Symposium of CIPA, Kyoto, Japan. October 11-15.

Miller, G. S. 1972. Hellenistic Macedonian Architecture: Its Style and Painted Ornamentation. Michigan: University Microfilms International.

Miller, G. S. 1982. "Macedonian tombs: Their Architecture and Architectural Decoration." In Macedonia and Greece in Late Classical and Early Hellenistic Times. Edited by B.Barr-Sharrar and E.N. Borza. Studies in the History of Art 10. 153-171. Washington: National Gallery of Art.

Miller, G. S. 1993. The tomb of Lyson and Kallikles: a painted Macedonian tomb. Mainz am Rhein: P. von Zabern.

Pantermalis, D., 1972. The new Macedonian tomb of Vergina. Maedonika v.12, 147-182. doi:http://dx.doi.org/10.12681 /makedonika.1003, Thessaloniki (in Greek). 
Pantermalis, D., 1985. The Macedonian tombs of Pieria. The archaeologists talk about Pieria, 9-13. Thessaloniki NELE of Pieria (in Greek).

Patay-Horvath. 2011. The complete virtual 3D reconstruction of the east pediment of the temple of Zeus at Olympia. Proceedings of 3DArch, Trento, Italy, March 2-4.

Saatsoglou - Paliadeli, C. 2011. "The Arts at Vergina-Aegae, the Cradle of the Macedonian Kingdom." In Brill's companion to ancient Macedon: studies in the archaeology and history of Macedon, 650 BC-300 AD. Edited by Robin J. Lane Fox. 271295. Leiden, Boston.

Sismanidis, K., 1985. Macedonian tombs in Thessaloniki. Thessaloniki I, 35-70. KITh (in Greek).

Sismanidis, K., 1997. Beds and bed-like constructions of Macedonian tombs. Athens, TAPA (in Greek).

Themelis, P., G., Touratsoglou, G., P., 1997. The tombs of Derveni. Athens TAPA (in Greek).

Tzanavari, K., 1997. Derveni: A necropolis of the ancient Lete. AEMTh 10 1996 , 461-476. Thessaloniki, Min. of Culture. \& AUTh (in Greek).

Tzanavari, K., 2000. Derveni of Lete. AD 50 Chronika $B^{\prime} 2$ 1995, 468-470. www.macedoniantombmacridybey.culture.gr (in Greek).

Valle Melon J.M., Lopetegi Galarraga A., Rodriguez Miranda A. 2005. Problems when generating virtual models representing real objects: Hondarribia walls. Proceedings of Virtual Retrospect, Biarritz, France. November 2-10.

www.macedoniantombmacridybey.culture.gr (last accessed 17.03.2019) 